\title{
Montastruc-Saves
}

Ancienne église Saint-Martin

\section{Alain Costes}

\section{(2) OpenEdition}

1 Journals

Édition électronique

URL : http://journals.openedition.org/adlfi/10432

ISSN : 2114-0502

Éditeur

Ministère de la culture

Référence électronique

Alain Costes, "Montastruc-Saves », ADLFI. Archéologie de la France - Informations [En ligne], Midi-

Pyrénées, mis en ligne le 01 mars 1997, consulté le 02 mai 2019. URL : http://

journals.openedition.org/adlfi/10432

Ce document a été généré automatiquement le 2 mai 2019.

(C) Ministère de la Culture et de la Communication, CNRS 


\title{
Montastruc-Saves
}

\author{
Ancienne église Saint-Martin
}

\section{Alain Costes}

Date de l'opération : 1989 - 1990 (SU)

Inventeur(s) : Costes Alain

1 Les vestiges extrêmement ruinés de l'ancienne église paroissiale se situent dans un secteur destiné à l'aménagement d'un espace vert, à quelque distance du château cité dès 1543 . C'est un édifice modeste, de plan rectangulaire ( $18 \mathrm{~m} \times 9 \mathrm{~m})$, prolongé au nord par une petite chapelle latérale $(4,50 \mathrm{~m}$ x 3,70 m), mentionné par le procès-verbal d'une visite pastorale de 1763 : celui-ci indique la nécessité de réparations dont le devis sera exécuté.

2 Alors que la population du village atteignait deux cent huit habitants en 1741 et deux cent quatre en 1793, les registres paroissiaux conservés aux Archives départementales pour l'année 1673 et les années 1737-1773 font état de cent cinquante décès dont $40 \%$ concernent des enfants en bas âge : la majorité est inhumée dans le cimetière entourant l'église, mais treize personnes - dont sept d'une même famille et un seul enfant - sont inhumés dans l'église même. Elle est pratiquement abandonnée dès 1830, puis en partie restaurée et transformée en chapelle privée durant quelques années alors qu'une nouvelle église est construite à un autre emplacement. Le cimetière est désaffecté vers 1870 et les matériaux de la construction seront progressivement récupérés.

Les fouilles ont permis, à la suite du dégagement du mur septentrional de l'église, d'explorer partiellement les abords et l'intérieur de la chapelle latérale, l'intérieur de la nef et le secteur le plus ancien du cimetière.

Dans l'église, les restaurations du XIXe s. sont représentées par un dallage qui a remplacé le sol aménagé à la fin du siècle précédent. Un sol antérieur a été repéré à $0,30 \mathrm{~m}$ sous ce niveau, bouleversé par les inhumations réalisées durant le XVIII ${ }^{\mathrm{e}} \mathrm{s}$. Le remblai intercalaire a livré des fragments de céramique et des monnaies de la première moitié du XVII $s$. 
5 Entre le début de ce siècle et la fin du siècle suivant, des sépultures en cercueil ont été creusées dans la nef: huit d'entre elles ont été rencontrées, qui témoignent d'une position relativement constante des inhumés : décubitus dorsal, les mains jointes sur le thorax ou le bas-ventre retenant parfois un chapelet. La chapelle latérale contenait cinq sépultures.

6 Le mobilier recueilli dans les sols ou le comblement des fosses est attribuable dans son ensemble à la première moitié du XVII ${ }^{\mathrm{e}} \mathrm{s}$. : bols à glaçure jaune sur engobe, plats à marli, vases des ateliers de Rieumes.

7 La fouille du secteur le plus ancien du cimetière, localisé à l'est de l'église, a livré quarante-six inhumations dont six seulement correspondent à des enfants, ce qui laisse supposer qu'un secteur particulier était réservé à leur sépulture. Le mobilier d'accompagnement est composé pour l'essentiel de chapelets à perles de verre ou de buis, et de rares médailles de pèlerinage (Notre-Dame-de-Montserrat) ou monnaies (trois double-tournois de Louis XIII).

8 Selon l'auteur de la fouille, il semble que l'église paroissiale et le cimetière aient été créés à la fin du XVI ${ }^{\mathrm{e}}$ s. ou au début du XVII ${ }^{\mathrm{e}}$ s. sur un terrain exempt de vestiges antérieurs, et que la partie orientale du cimetière ait été abandonnée dès la seconde moitié $d u \mathrm{XVII}^{\mathrm{e}} \mathrm{s}$. : d'autres hagiotoponymes peuvent correspondre, dans les environs du site, à l'existence d'une église paroissiale antérieure qui se trouvait peut-être au voisinage immédiat du château.

\section{INDEX}

Index chronologique: Temps Modernes

Index géographique : Midi-Pyrénées, Haute-Garonne (31), Montastruc-Savès

operation Sauvetage urgent (SU)

anthroponyme Louis XIII 